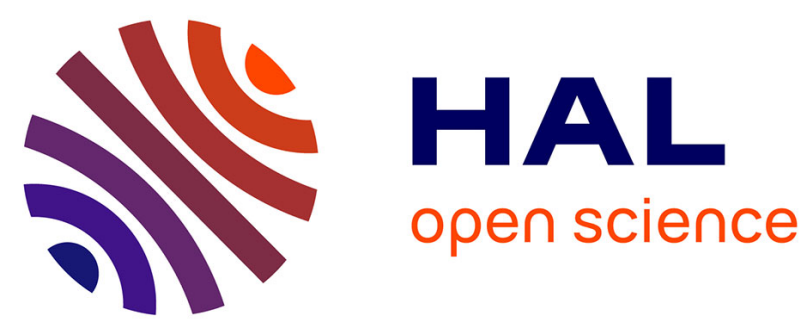

\title{
AN FIM STUDY ON THE INITIAL STAGE OF THE SURFACE REACTION OF TUNGSTEN WITH n-OCTANOL UNDER AN APPLIED DC VOLTAGE
}

T. Terao, F. Iwatsu, Naoto Morikawa

\section{- To cite this version:}

T. Terao, F. Iwatsu, Naoto Morikawa. AN FIM STUDY ON THE INITIAL STAGE OF THE SURFACE REACTION OF TUNGSTEN WITH n-OCTANOL UNDER AN APPLIED DC VOLTAGE. Journal de Physique Colloques, 1989, 50 (C8), pp.C8-315-C8-319. 10.1051/jphyscol:1989853 . jpa00229951

\section{HAL Id: jpa-00229951 https://hal.science/jpa-00229951}

Submitted on 1 Jan 1989

HAL is a multi-disciplinary open access archive for the deposit and dissemination of scientific research documents, whether they are published or not. The documents may come from teaching and research institutions in France or abroad, or from public or private research centers.
L'archive ouverte pluridisciplinaire $\mathbf{H A L}$, est destinée au dépôt et à la diffusion de documents scientifiques de niveau recherche, publiés ou non, émanant des établissements d'enseignement et de recherche français ou étrangers, des laboratoires publics ou privés. 
COLLOQUE DE PHYSIQUE

Colloque C8, Supplément au $\mathrm{n}^{\circ} 11$, Tome 50, novembre 1989

C $8-315$

AN FIM STUDY ON THE INITIAL STAGE OF THE SURFACE REACTION OF TUNGSTEN WITH n-OCTANOL UNDER AN APPLIED DC VOLTAGE

T. TERAO, F. IWATSU and H. MORIKAWA

Department of Materials Science and Engineering Nagoya Institute of rechnology Gokiso-cho, Showa-ku, Nagoya 466, Japan

\begin{abstract}
The surface reaction of tungsten with n-octanol under a pulse with a height of about +10V, a risetime of lonsec, and a width of several seconds, which gives rise to interesting FI images of the central (110) plane split into two parts across the [001] zone line or into more than two parts, has been studied in order to reveal the reaction process from the initial stage to the final splitting by 1) decreasing the pulse width to shorten the reaction time and by 2) adding benzene to n-octanol to mitigate the activity of the latter. In the initial stage no damage was observed on the (110) plane but small shallow basins were observed near <131> poles. As the reaction proceeded, they became larger and extended toward the center of the (110) plane. It has been concluded that the reaction starts in areas around $\langle 131\rangle$ poles and proceeds to widen the corroded areas and finally links them on the (110) plane to split it.
\end{abstract}

\title{
1-INTRODUCTION
}

During the pursuit of the availability of field ion microscopy in the investigation of metal-liquid interfacial reactions, quite interesting field ion images of tungsten and molybdenum tips have been obtained in which the central (110) plane, the stablest plane among those of bcc metals, is split into two parts across the [001] zone line when a pulse with an amplitude of about lov, a risetime as short as 10nsec, and a duration of several seconds is applied to a tip being immersed in n-octanol $\left(^{(}\right)$. The tip cap thus obtained has been shown to have a rather deep groove running through the (110) plane along the [001] zone line. In the previous paper [1], we reported the detailed shape of a tungsten tip cap with a deep pit thus made in a split central (110) plane. The reaction sometimes proceeded so far that the central (110) plane split into more than two, even five, parts. Decreasing the pulse height seemed not to alter the reaction except that the probability of occurrence of the split decreased. Besides the split images, tungsten tips subjected to this treatment have given various types of FI images which correspond to various stages of the reaction. Typical FI images are shown in Fig. 1. As can be seen in the images the central (110). plane is not damaged when the surface does not change appreciably from the original field evaporation end form. These images suggest that the splitting of (110) plane is an advanced stage of the reaction which has started somewhere outside the (110) plane.

In the present paper, some results are presented of experiments designed to elucidate the initial stage of the reaction and the successive stages leading to the splitting.

() Iwatsu, F., Morikawa, H. and Terao, T., in preparation. 


\section{2-EXPERIKENTAL}

The apparatus and procedure were the same as described elsewhere[1, 2]. The pulse with a height of $+10 \mathrm{~V}$, a risetime of 1onsec, and a duration of $3.2 \mathrm{sec}$ was employed as a standard pulse in the present study unless otherwise stated.

In order to reveal the reaction process from the initial stage through to the final splitting, the following two kinds of experiment were carried out:

1) The duration of the pulse was decreased in order to shorten the reaction time.

2) Benzene, which is inert to tungsten as will be shown below, was added to n-octanol in order to mitigate the activity of the latter to tungsten.

\section{3-RESULTS AND DISCUSSION}

In Fig. 2 are shown two FI images which were obtained when the pulse width was decreased to one tenth\{Fig. 2(a)\} and to a half\{Fig. 2(b)\} of that of the standard pulse. In the former micrograph, three rather wide dark areas are seen around $\langle 131\rangle$ and $\langle 151\rangle$ poles. they are situated almost symmetrically with respect to the [001] zone line, their tails reaching the center of the (110) plane. In Fig. 2(b) the central (110) plane is split into three parts which are situated side by side along the [110] zone line. There is a groove along the [001] zone line which goes between the central and the right-hand split (110) planes. There are also two areas with irregular plane rings in the upper left and lower part of the micrograph which extend toward the narrow area between the central and the left-hand split (110) planes. A simmilar micrograph but showing less severely damaged surfaces than those in Fig. 2(b) was obtained when a pulse with a height of $+8 \mathrm{~V}$ was applied to a tungsten tip (see Fig. 3). There are several narrow dark areas which extend toward the center of (110) plane. This micrograph seems to show the state of the surface just when the reaction is about to split the central (110) plane.

The application of the standard pulse to a tungsten tip while it is immersed in pure benzene did not give rise to any change on the tip surface. Because this particular pulse, when applied to a tungsten tip being immersed in n-octanol, gives the split in the tip without fail, benzene is inactive to tungsten surfaces even when the standard pulse is applied. The addition of benzene to n-octanol, therefore, will mitigate the action of the latter to tungsten surfaces and will allow us to see the initial stage of the reaction of n-octanol with the tip surfaces. Figure 4 shows a FI image taken after the standard pulse was applied to a tungsten tip while it was immersed in $n-$ octanol added with benzene to $5 \%$. We can see many small dark areas scatter around <131> and <151> poles, the central (110) plane being devoid of them. These dark areas eventually disappeared as the tip surface was field evaporated, indicating that they are images of shallow basins made in the initial stage of the reaction.

Now we can draw a brief feature of the reaction process from the images given above. As can be seen from Figs. 1(b), (c), 2 (a) and (b), very little damage is observed in the triangular region enclosed by the poles [110], [121] and [211] and in its equivalent regions even when the central (110) plane is split. It is suggestive that when the central (110) plane is split, the grooves between the split planes do not run parallel with the [110] zone line but incline to divert from it \{see Figs. 1(c), (d), and 2(b)\}. In cases where the splitting does not occur, corroded areas seem to exist in the triangular regions enclosed by [110], [121] and [130] poles and in its equivalent regions \{Figs. 1(b), 2(a) and (3) \}. The image in Fig. 4, which seems to represent very early stage of the reaction, shows that dark areas are present in directions from the central [110] pole to $\langle 131\rangle$ and $\langle 151\rangle$ poles. It is interesting to note that there are dark corroded areas seen 
also in the equivalent areas around the peripheral <110> poles as indicated by the arrows in Figs. $1(b)$ and (c). Arranging the images in the order Figs. 4, 3, 1(b), 2(a) and (b), we can imagine how the reaction proceeds from the initial stage to the final splitting. Our conclusion is, therefore, that "splitting" of the (110) plane occurs when shallow basins made in the initial stage of the reaction around <131> poles become larger and deeper as the reaction proceeds, and they eventually link each other on the (110) plane to split it into two parts across the [001] zone line or even to four parts with $\mathrm{X}$-shaped crossed lines of division. This process is shown schematically in Fig. 5. The appearance of the split obtained depends on how the corroded areas link each other on the (110) plane.

\section{References}

[1] Terao, T., Kozakai, M., Iwatsu, F., Suzuki, Y., Morikawa, H. and Yashiro, Y., Proc. 29th Intern. Field Emission Symp. (Göteborg, 1982) p. 211 .

[2] Terao, T, Iwatsu, F., Morikawa, H. and Yashiro, Y., J. de Physique 48 (1987), C6-499.

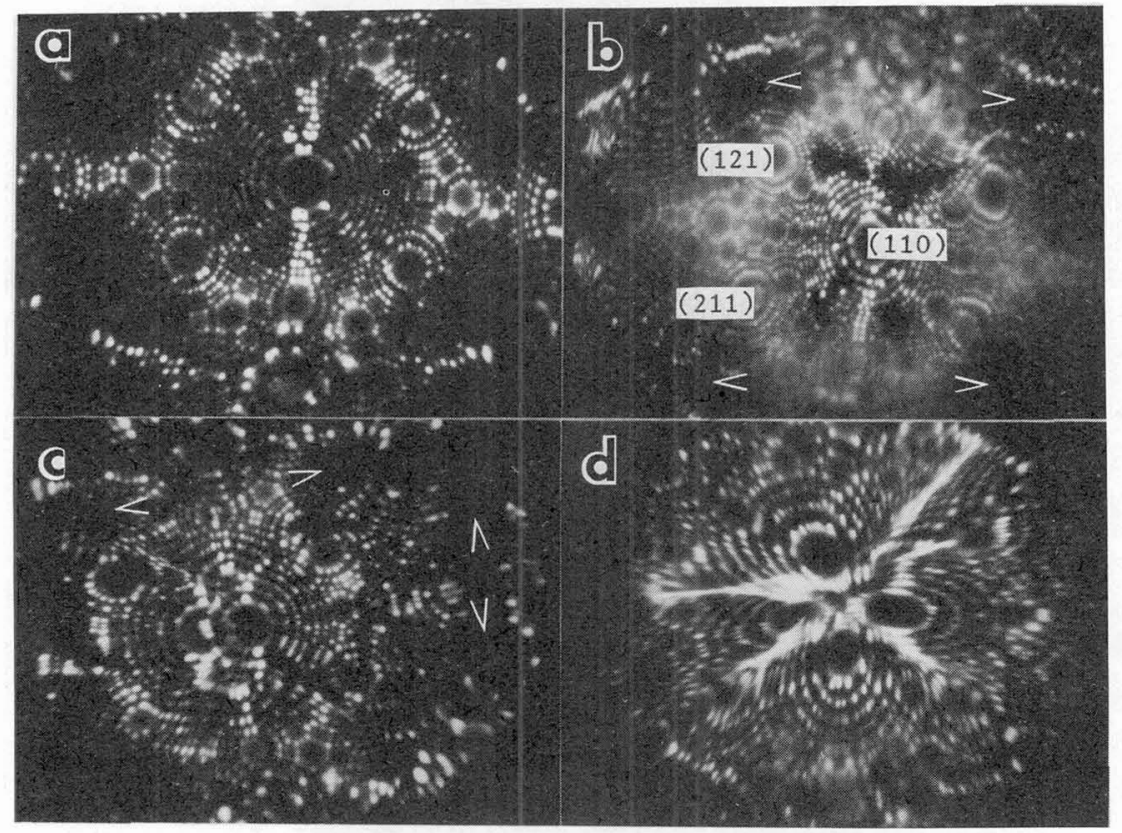

Fig. 1. Typical FI images of tungsten after the reaction. (a) Before and (b) -(d) after the application of the standard pulse (see the text). 


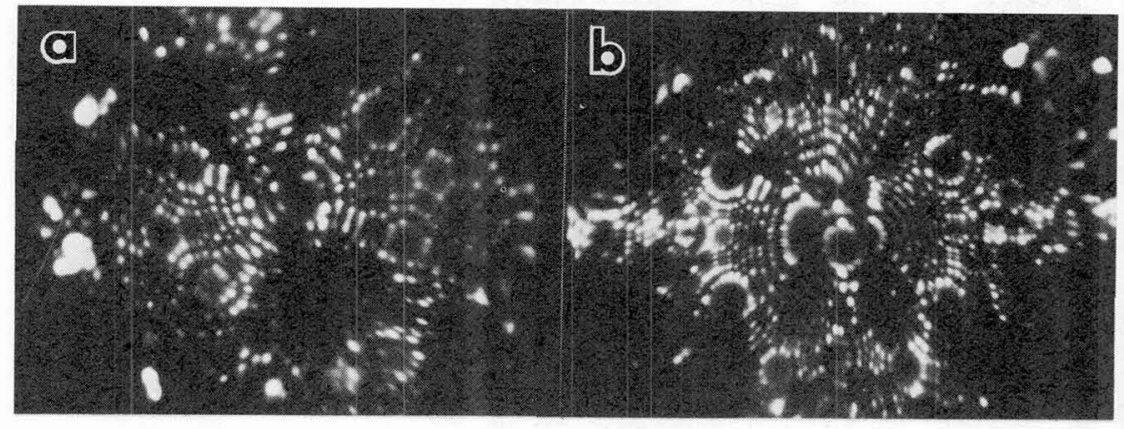

Fig. 2. FI images after the application of a pulse with a shorter width. (a) $0.32 \mathrm{sec}$, (b) $1.6 \mathrm{sec}$.

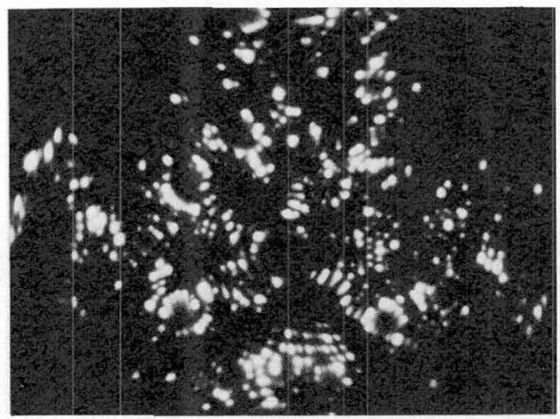

Fig. 3. A FI image after the application of a pulse with a height of $+8 \mathrm{~V}$.

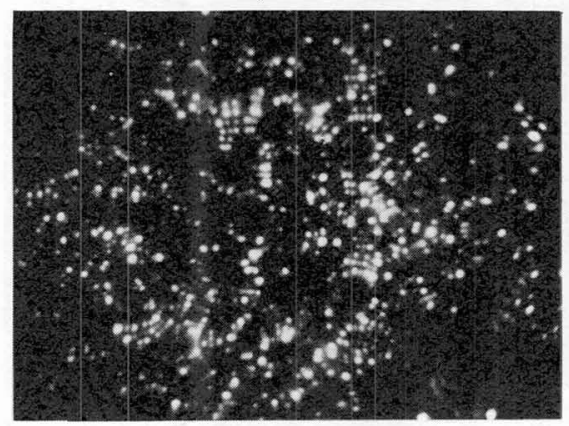

Fig. 4. A FI image after the application of the standard pulse while the tip is immersed in n-octanol containing $5 \%$ of benzene. 


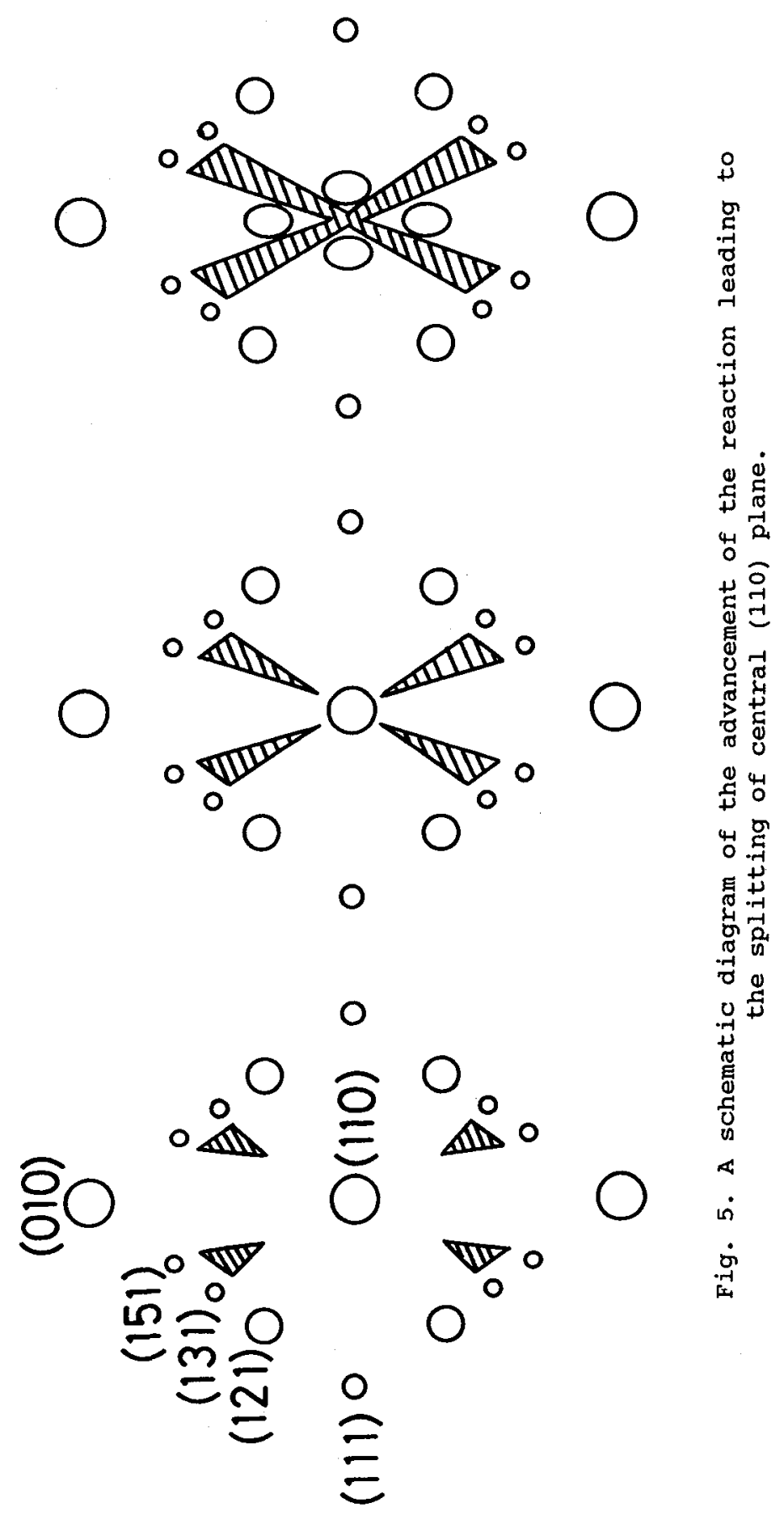

